Author(s):

Submitted to:
Fernando Garzon, MST-11

Eric Brosha, MST-11

\section{RECEIVED \\ NOV 141996 \\ OSTI}

DOE Office of Scientific and Technical Information (OSTI)

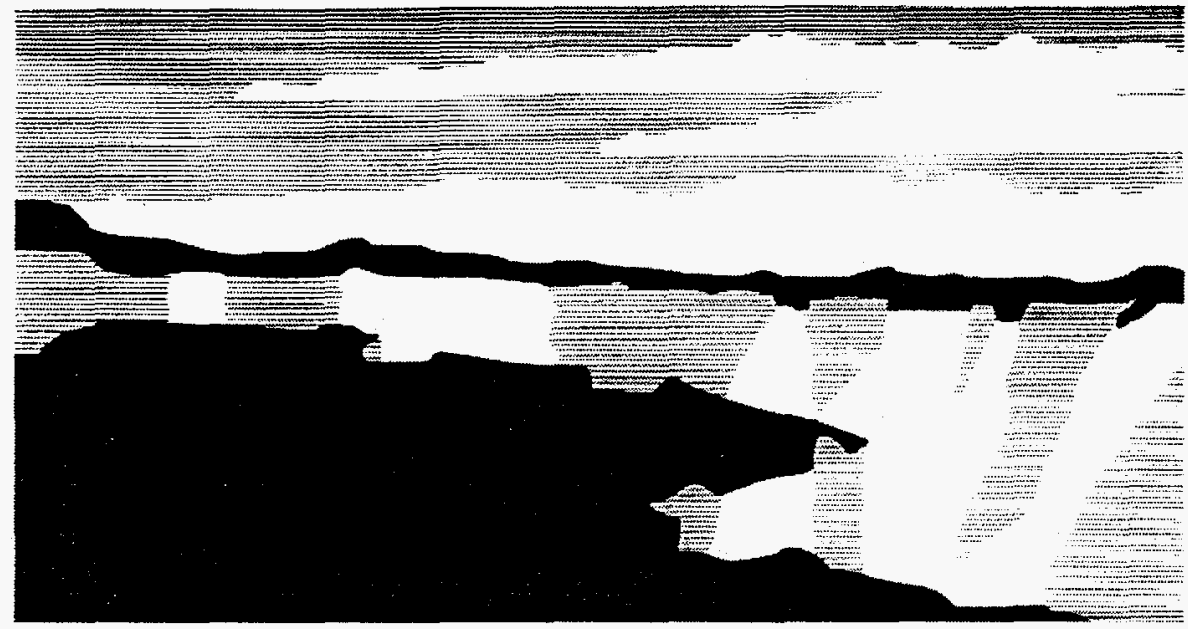

Los Alamos National Laboratory, an affirmative action/equal opportunity employer, is operated by the University of California for the U.S. Department of Energy under contract W-7405-ENG-36. By acceplance of this anticle, the publisher recognizes that the U.S. Government retains a nonexclusive, royaltyfree license to publish or reproduce the published form of this contrbution, or to allow others to do so, for U.S. Government purposes. The Los Alamos National Laboratory requests that the publisher identify this article as work performed under the auspices of the U.S. Department of Energy. 


\section{DISCLAIMER}

Portions of this document may be illegible in electronic image products. Images are produced from the best available original document. 


\section{DISCLAIMER}

This report was prepared as an account of work sponsored by an agency of the United States Government. Neither the United States Government nor any agency thereof, nor any of their employees, makes any warranty, express or implied, or assumes any legal liability or responsibility for the accuracy, completeness, or usefulness of any information, apparatus, product, or process disclosed, or represents that its use would not infringe privately owned rights. Reference herein to any specific commercial product, process, or service by trade name, trademark, manufacturer, or otherwise does not necessarily constitute or imply its endorsement, recommendation, or favoring by the United States Government or any agency thereof. The views and opinions of authors expressed herein do not necessarily state or reflect those of the United States Government or any agency thereof. 


\title{
Novel Electrocatalytic Sensors
}

\author{
Fernando Garzon* and Eric Brosha
}

\begin{abstract}
This is the final report of a one-year, Laboratory-Directed Research and Development (LDRD) project at the Los Alamos National Laboratory (LANL). The basic principles employed for previously developed oxygen and sulfur dioxide sensors have been applied to other chemical sensor needs. The oxide electrodes used for oxygen sensors also possess novel catalytic properties that have been utilized for the detection of $\mathrm{CO}$ through the use of electrocatalysts on solid electrolyte membranes. These metal oxides offer the ability to catalyze reactions selectively for oxidation and/or reduction of analyte gas species. A combination of a catalytic and a non-catalytic electrode deposited on a solid electrolyte was used to sense the reactive species by locally changing the oxygen concentration on the electrode surfaces. Multiple species can be sensed on a single substrate through the use of different electrocatalysts. A related concept is to control the catalytic properties of these materials by controlling the oxygen stoichiometry using an electrochemical pump. The presence of a gas species was sensed by changes in the electronic conductivity of the semiconducting electrode layer.
\end{abstract}

\section{Background and Research Objectives}

Carbon monoxide gas ( $\mathrm{CO})$ is a deadly, colorless, odorless gas that results from incomplete combustion of typical fuels. It is the most common cause of death among asphyxiant gases in the United States. Better sensor technologies for this gas are needed to protect people in their workplaces and homes. The objective of this project was the development of simple, low-cost electrochemical sensors for the detection of $\mathrm{CO}$ in air with tens of parts per million sensitivities, good selectivity, and fast response times. The current commercial sensor technologies cannot detect carbon monoxide below dangerous threshold levels (tens of ppm), nor do they respond quickly at the hundreds of ppm levels.

* Principal investigator, e-mail: garzon@lanl.gov 


\section{Importance to LANL's Science and Technology Base and National R\&D Needs}

This project supports Los Alamos core competencies in earth and environmental systems as well as nuclear and advanced materials. It enhances the visibility of the Laboratory in the area of sensor development and increases our ability to respond to initiatives requiring sophisticated sensors.

\section{Scientific Approach and Results to Date}

Past research efforts in solid state electrochemical sensors for carbon monoxide detection have used two strategies. In one approach, Williams, et . al., utilized two different noble metal electrodes (one gold and the other platinum) separated by an yttrium-zirconium oxide oxygenion conductor (Figure 1). The device operates by the principle that when both electrodes are exposed to the same gas stream containing $\mathrm{CO}$ and oxygen, two competing reactions occur on each electrode surface, the reduction of oxygen $\left(1 / 2 \mathrm{O}_{2}(\mathrm{~g})+2 \mathrm{e}^{-}=\mathrm{O}^{-2}\right)$ and the oxidation of $\mathrm{CO}$ to carbon dioxide $\left(\mathrm{CO}(\mathrm{g})+\mathrm{O}^{-2}=\mathrm{CO}_{2}(\mathrm{~g})+2 \mathrm{e}^{-}\right)$. If no current is allowed to flow through the electrolyte, the two reactions on each electrode surface will reach an equilibrium localexchange current, i.e., the rate of oxygen reduction will equal the rate of $\mathrm{CO}$ oxidation. However, the combined reaction rate on the surface of the gold electrode is not the same as the combined rate on the platinum. Since the local exchange-current density depends on surface coverage of several species and on reaction rate constants, these will, in general, be different for different electrode materials. The result is a measured electric potential across the yttriumzirconium oxide electrolyte due to a difference in oxygen activity (oxygen chemical potential or oxygen partial pressure) across the electrolyte.

The CO sensor reported by Tan, et. al., functions on the same principles discussed in the paragraph above; however, they did not utilize two different metal electrodes to provide differing oxidation and reduction (redox) rates across an oxygen ion conductor. Instead, they used two platinum electrodes. The different redox rates were obtained by coating one of the platinum electrodes with a mixture of $\mathrm{CuO}$ and $\mathrm{ZnO}$ (Figure 2). This two-phase mixture of the oxides of copper and zinc is a known $\mathrm{CO}$ oxidation catalyst. As above, the differing rates of CO oxidation lead to a difference in oxygen chemical potential across the solid electrolyte, which leads to a measurable response in the form of an electric potential across the sensor.

The operating principle behind our sensor is the same as that of Williams and Tan. Our sensor design differs in that we utilized a fully dense thin film of a mixed electronic and ionic conducting and catalytic metal oxide, such as $\mathrm{La} 0.8 \mathrm{Sr} 0.2 \mathrm{CoO}$, deposited by an $\mathrm{RF}$ magnetron 
sputtering vapor deposition process onto a thin yttrium-zirconium oxide solid electrolyte (Figure 3). A thin film of $\mathrm{La} 0.8 \mathrm{Sr} 0.2 \mathrm{CoO} 3$, approximately $1000-2000 \AA$ thick, is necessary to ensure a fast response to $\mathrm{CO}$. The sensor response characteristics of thick films (on the order of $1 \mu \mathrm{m}$ thick) begin to degrade due to the large oxygen storage capacity of $\mathrm{La0} .8 \mathrm{Sr}_{0.2} \mathrm{CoO}_{3}$. The use of a thin electrolyte also improves response time. We used $500 \mu \mathrm{m}$-thick CeraFlex brand electrolyte cut to $1 \mathrm{~cm}^{2}$ pieces. The perovskite $\mathrm{La0} .8 \mathrm{Sr}_{0.2} \mathrm{CoO}_{3}$ is used because it exhibits intrinsic catalytic activity for the oxidation of $\mathrm{CO}$. This property is probably the result of strong cobalt ion-carbon monoxide ligand interactions. Since $\mathrm{La}_{0.8} \mathrm{Sr}_{0.2} \mathrm{CoO}_{3}$ is an electronic conductor, no auxiliary metal electrode is required. The counter electrode is a sputtered film of gold, which is a poor CO oxidation catalyst, approximately $2500 \AA$ thick. The response time of this sensor to carbon monoxide is shown in Figure 4. Note the small response to relatively high concentrations of hydrogen, a very reactive interference gas.

This configuration offers several performance advantages over those designs presented by Tan and Williams: (1) increased sensitivity; (2) higher operating temperatures, and thus a wide operating window; and (3) faster response time. Figure 5 is a plot that compares $\mathrm{CO}$ response data from Tan, et. al., (which is superior to the Williams device) to our data. Both sets were acquired at $500^{\circ} \mathrm{C}$ and in an air background. Although our data were taken at a lower $\mathrm{CO}$ concentration range (less than $500 \mathrm{ppm}$ ), the data indicate a much larger response output voltage and a greater slope. This indicates that our sensor design offers greater sensitivity to small quantities of $\mathrm{CO}$. The linear response in this $\mathrm{CO}$ concentration range is also highly desirable from an applications viewpoint.

The use of a metal oxide as a sensing electrode extends the operating temperature range. Figure 6 is a plot of our sensor compared to Tan, et. al., as a function of increasing temperature. Although the sensor output decreases with increasing temperature for both sensor designs, our sensor still exhibits appreciable sensitivity even at $700{ }^{\circ} \mathrm{C}$. Tan, et. al., examined the effect of increased temperature on their sensor output. They report that the maximum output obtained in air occurred around $350^{\circ} \mathrm{C}$. However, the lowest useful temperature range appears to be $400-450^{\circ} \mathrm{C}$, as the sensor response time greatly increases with decreasing temperature. Their data indicate that by $550^{\circ} \mathrm{C}$, the sensor output decreased by $90 \%$ of the output recorded at $400{ }^{\circ} \mathrm{C}$. It is important to emphasize that the output of our sensor at $700{ }^{\circ} \mathrm{C}$ exceeds the output reported by Tan, et. al. at $500^{\circ} \mathrm{C}$.

Our sensor offers not only a greater operating window, and thus an increased flexibility for use, but a faster response time as well. The response-time data reported by Tan indicates a 4-minute period is required to reach an equilibrium voltage value, as compared to a approximately 10-second response time for our sensor. This improvement in response time is 
attributable to the use of a mixed conducting-metal oxide as a sense electrode, use of a thin electrolyte, and operation at a higher temperature.

We also report the effect of current biasing on sensor response. The application of a small current bias to our sensor can preferentially improve or degrade the response depending on current-flow direction with respect to the metal oxide electrode. Figure 7 is a plot of $\mathrm{CO}$ response of our sensor taken at $500{ }^{\circ} \mathrm{C}$ showing the effects of current biasing. The application of $+0.15 \mu \mathrm{A}$ increases sensor output by almost $20 \mathrm{mV}$. By biasing the sensor such that oxygen ions flow through the electrolyte toward the $\mathrm{La0} .8 \mathrm{Sr} 0.2 \mathrm{CoO}_{3} \mathrm{film}$, the rate of $\mathrm{CO}$ oxidation is enhanced with respect to the rate of oxygen reduction on the gold surface. The result is an increase in sensor output because of an increased oxygen differential across the electrolyte. Reversing the current reverses the process, so that $\mathrm{La0} .8 \mathrm{Sr}_{0.2} \mathrm{CoO}_{3}$ becomes a poor $\mathrm{CO}$ oxidation catalyst and the sensor response decreases.

We have developed state-of-the-art, low-cost, solid-state electrochemical sensors with good selectivity, sensitivity, and fast response times to carbon monoxide gas. This technology appears to be very promising for commercialization to $\mathrm{CO}$ safety monitor systems. 


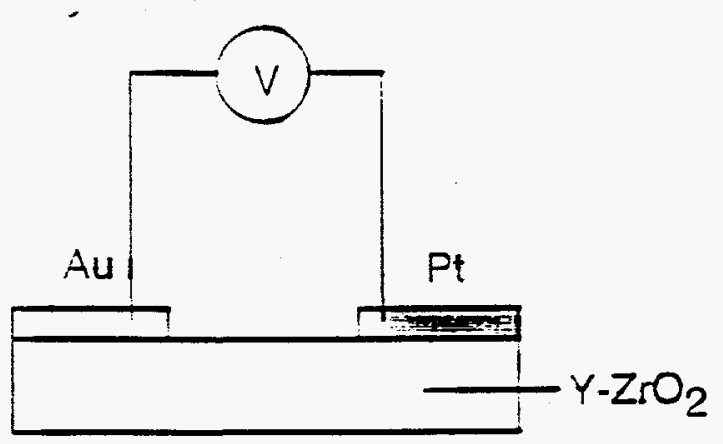

Figure 1. Mixed potential sensor reported by Williams, et. al.

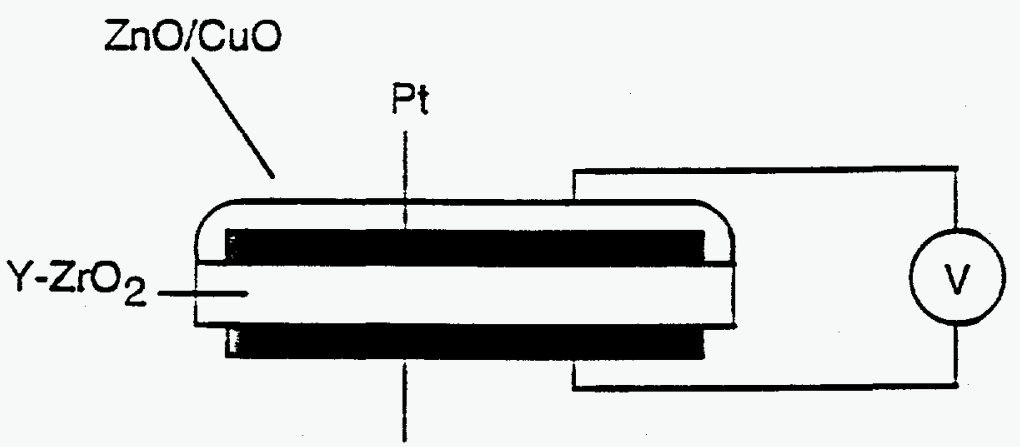

$\mathrm{Pt}$

Figure 2. Carbon monoxide sensor reported by Tan, et. al.

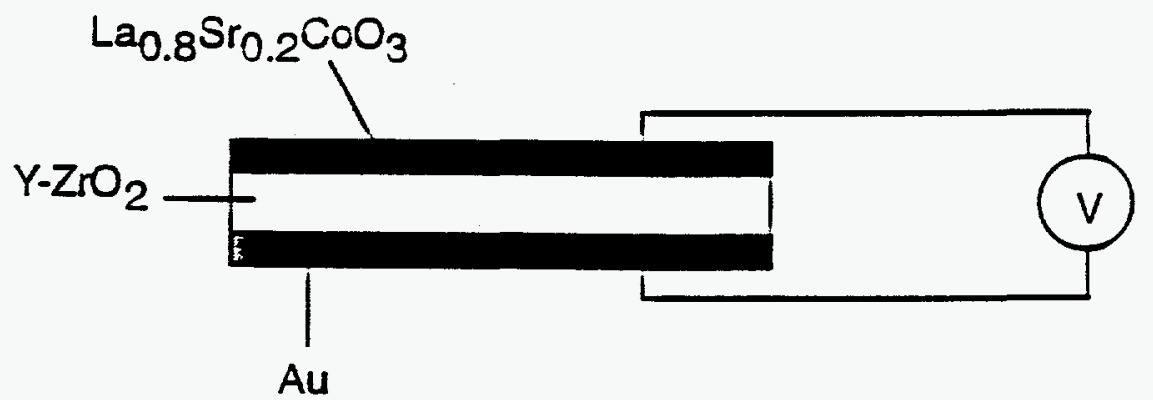

Figure 3. $\mathrm{La} 0.8 \mathrm{Sr}_{0.2} \mathrm{CoO}_{3}$-based $\mathrm{CO}$ sensors developed by the authors. 


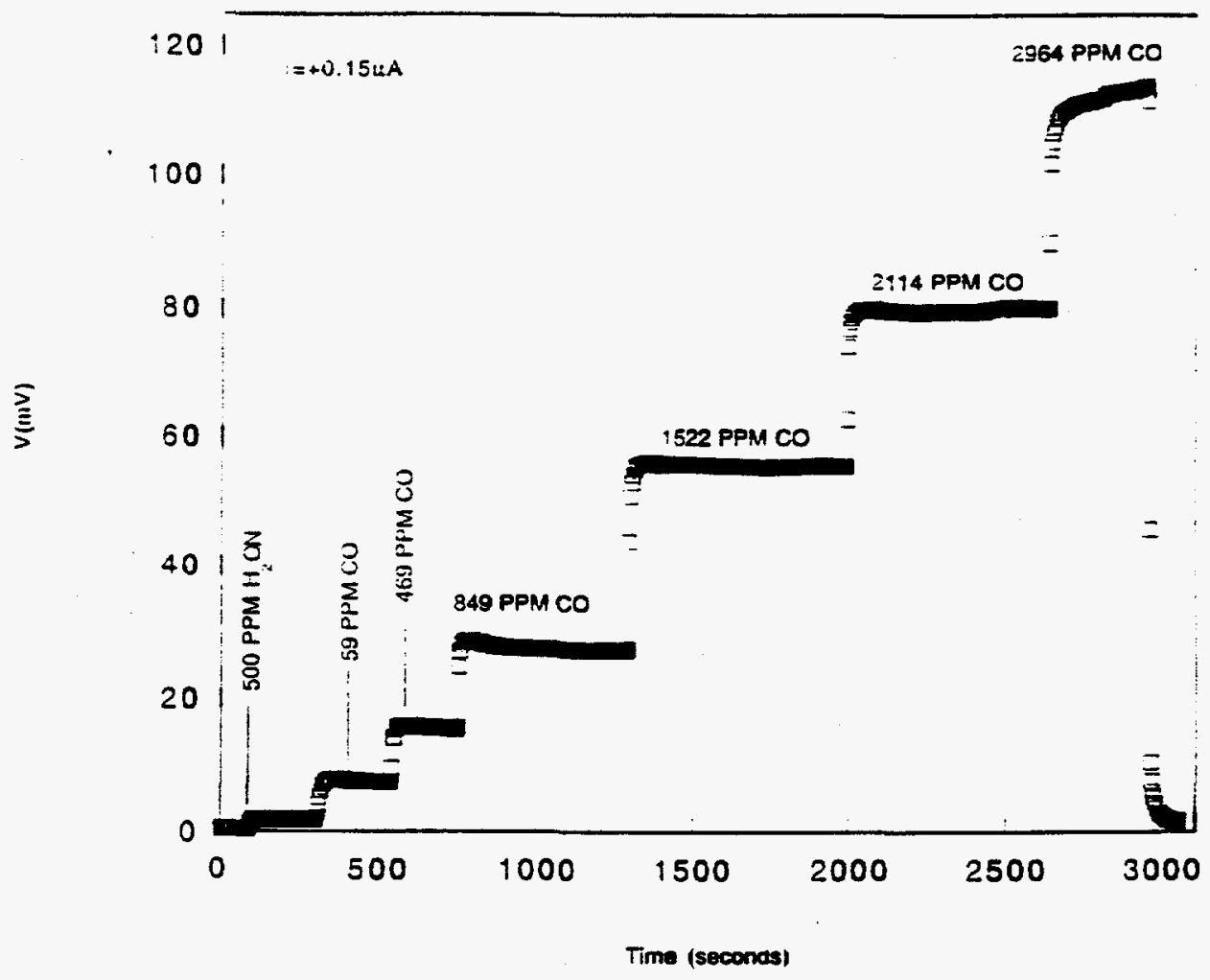

Figure 4. Sensor response at $650^{\circ} \mathrm{C}$ to hydrogen (interference gas) and varying concentrations of $\mathrm{CO}$ in air. 


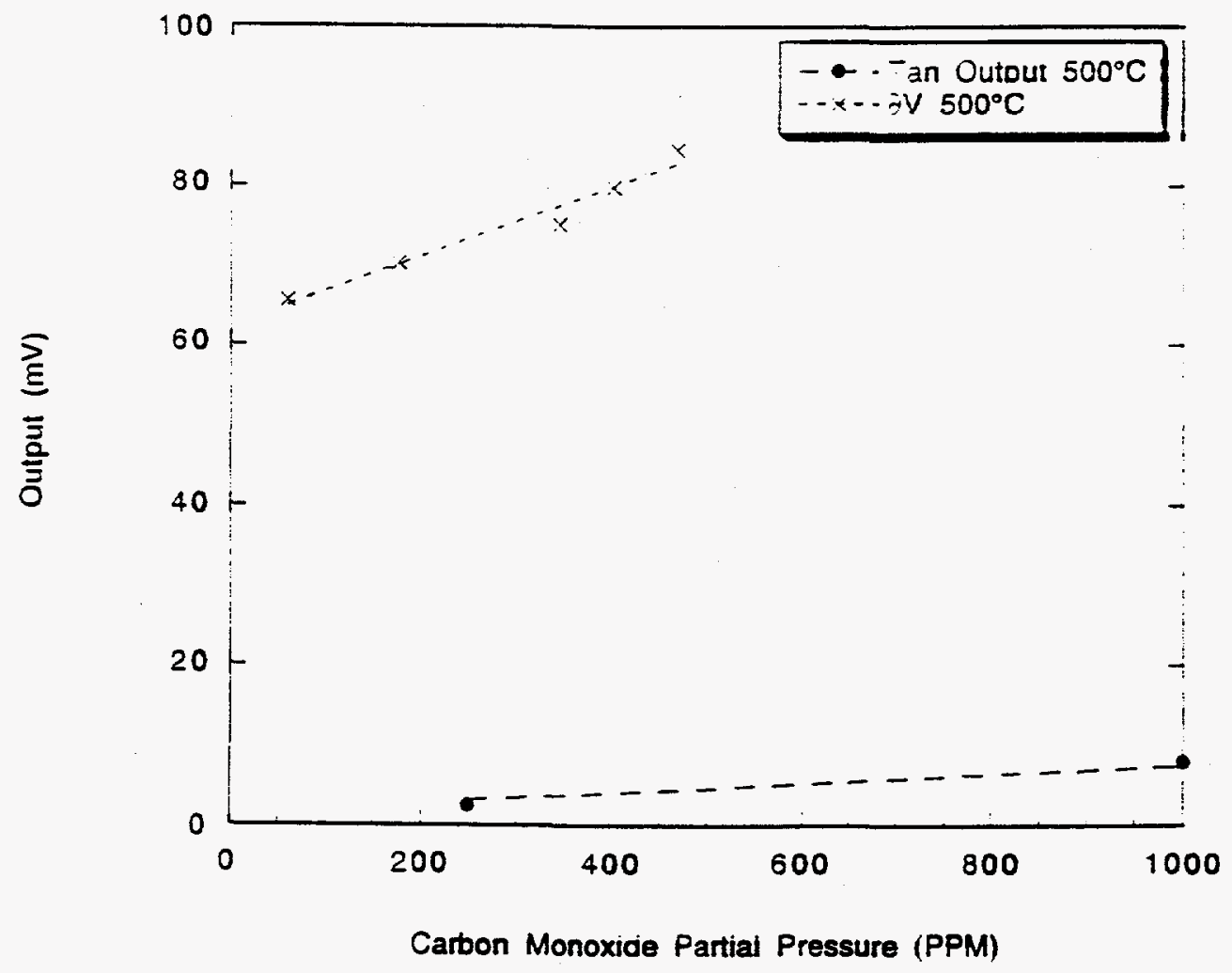

Figure 5. A comparison of $\mathrm{CO}$ sensor output between the authors' sensors and sensors of Tan, et. al., at $500^{\circ} \mathrm{C}$ and in an air background. 


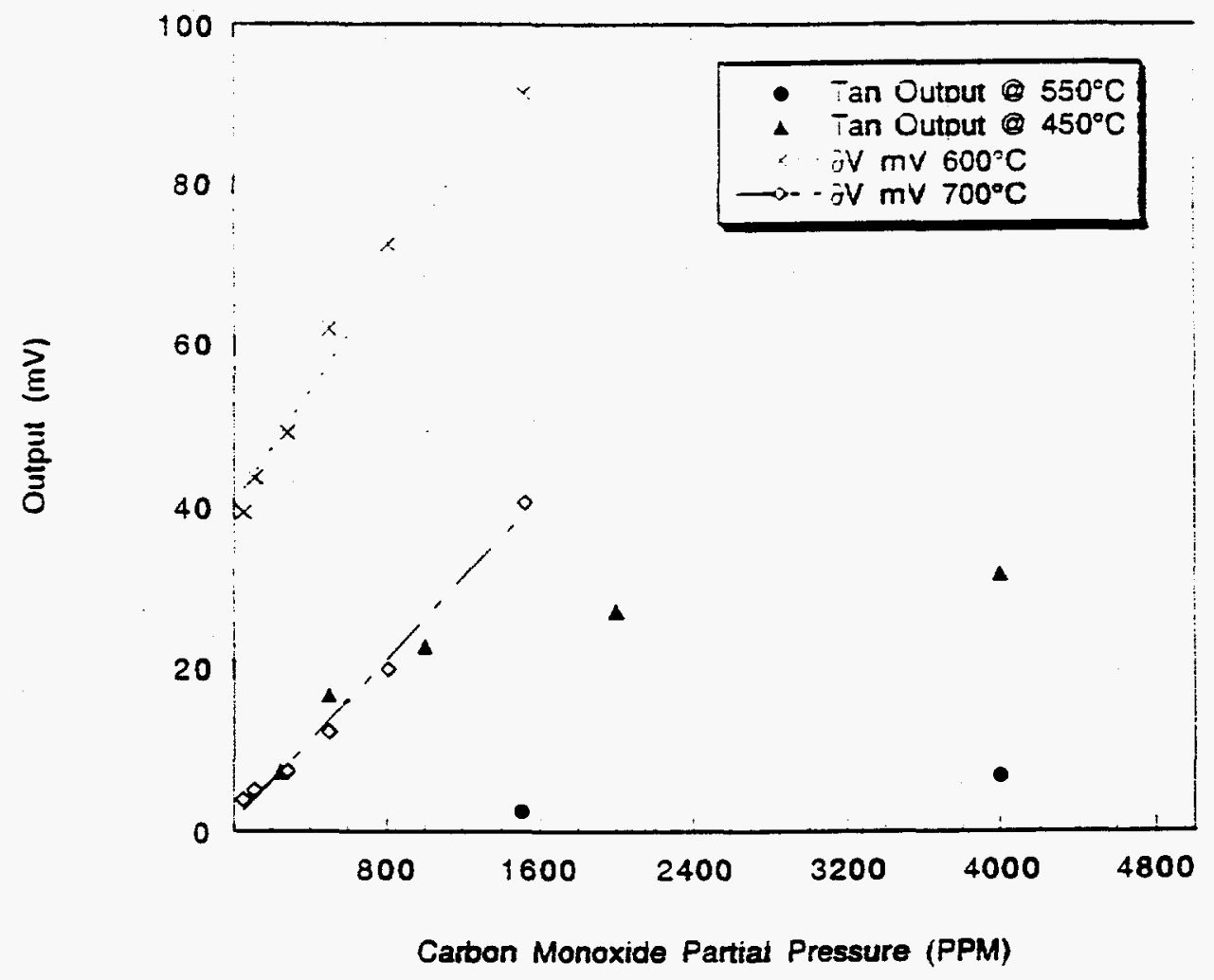

Figure 6. Temperature dependence of sensor response versus CO level. Data from the authors are plotted with line fits. 


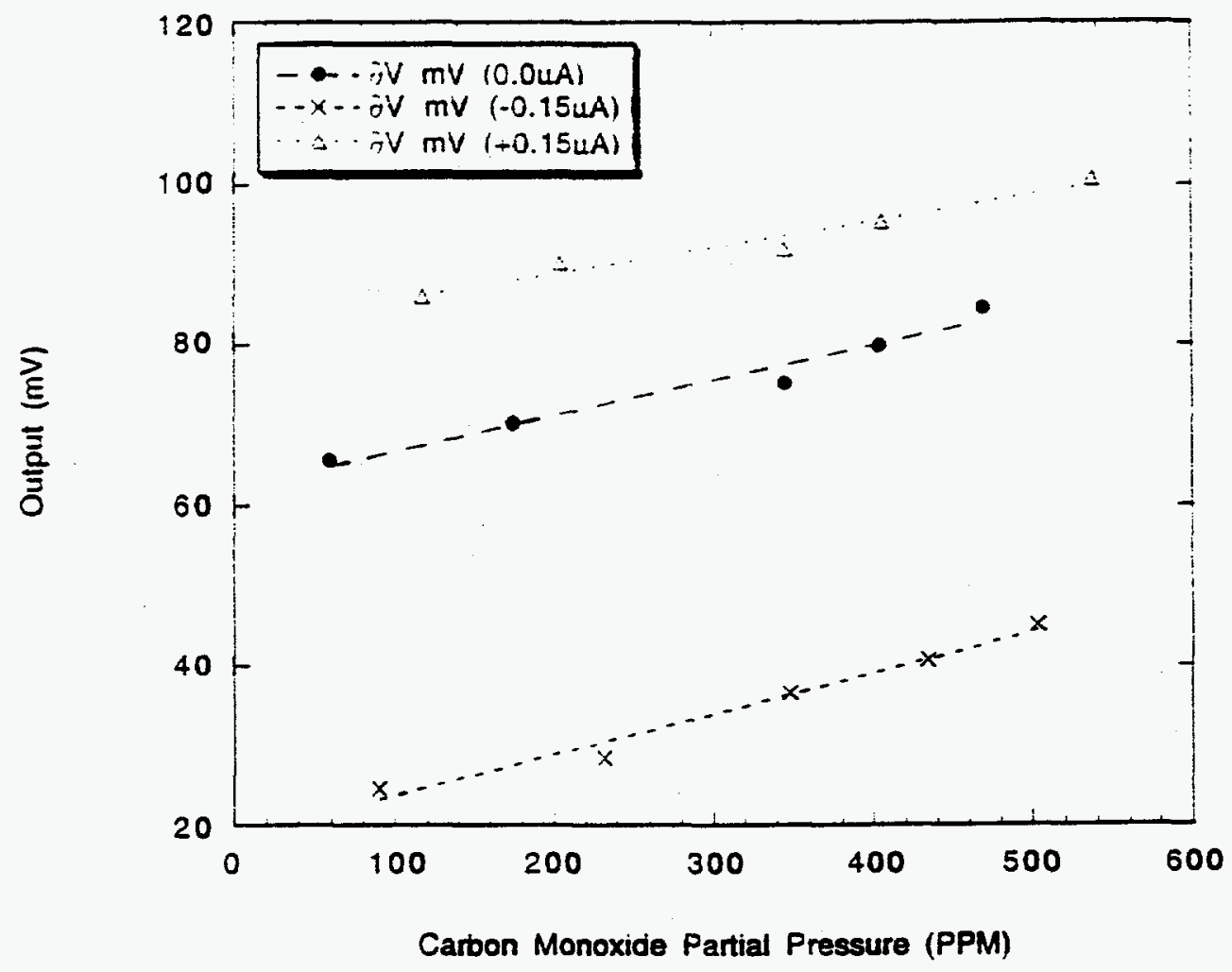

Figure 7. The effect of current biasing on a $\mathrm{La}_{0.8} \mathrm{Sr}_{0.2} \mathrm{CoO}_{3}$-based $\mathrm{CO}$ sensor. 